\title{
GCU
}

Glasgow Caledonian

University

University for the Common Good

\section{Determination of optimal site and capacity of DG systems in distribution network based on genetic algorithm}

Alhadi Al-Hamali, Abdul-Wahab; Farrag, Mohamed Emad; Bevan, Geraint; Hepburn, Donald M.

Published in:

52nd International Universities Power Engineering Conference (UPEC), 2017

DOI:

10.1109/UPEC.2017.8231996

Publication date:

2017

Document Version

Author accepted manuscript

Link to publication in ResearchOnline

Citation for published version (Harvard):

Alhadi Al-Hamali, A-W, Farrag, ME, Bevan, G \& Hepburn, DM 2017, Determination of optimal site and capacity of DG systems in distribution network based on genetic algorithm. in 52nd International Universities Power Engineering Conference (UPEC), 2017 ., 368, IEEE. https://doi.org/10.1109/UPEC.2017.8231996

\section{General rights}

Copyright and moral rights for the publications made accessible in the public portal are retained by the authors and/or other copyright owners and it is a condition of accessing publications that users recognise and abide by the legal requirements associated with these rights.

Take down policy

If you believe that this document breaches copyright please view our takedown policy at https://edshare.gcu.ac.uk/id/eprint/5179 for details of how to contact us. 


\section{Determination of Optimal Site and Capacity of DG Systems in Distribution Network based on Genetic Algorithm}

\author{
Abdulwahab Alhamali \\ Glasgow Caledonian \\ University, Glasgow, UK \\ Abdul.AlHamali@gcu.ac.uk
}

\author{
Dr. Mohamed Emad Farrag \\ Glasgow Caledonian \\ University, Glasgow, UK \\ Mohamed.Farrag@gcu.ac.uk
}

\author{
Dr. Geraint Bevan. \\ Glasgow Caledonian \\ University, Glasgow, UK \\ Geraint.Bevan@gcu.ac.uk
}

\author{
Dr. Donald M Hepburn \\ Glasgow Caledonian \\ University, Glasgow, UK \\ D.M.Hepburn@gcu.ac.uk
}

\begin{abstract}
Concerns over global climate changes coupled with growing demand for energy are leading to increased penetration of distributed generation from intermittent sources into low voltage networks. In such cases distribution network (DN) operation will be affected. Consequently, there have been serious concerns over reliability and satisfactory operation of these power systems which contain distributed generation (DG) equipment. Distributed power generated from renewable sources is variable particularly in the case of wind generation or solar energy. The variability affects the stability of the system between supply and consumers.

In DN, the losses and voltage drop across the network are significant matters and the DG location has a critical impact on the network operation. So, there is a clear need to optimise the DG size and location in the $\mathrm{DN}$; for example, optimising the number of DG's and coordinating their operation can improve voltage drop and network losses.

In this paper, an optimisation technique based on the genetic algorithm (GA) in conjunction with the power flow (PF) method is used to improve the DN performance and to identify the best location and size of the DG's. The main goal of the optimisation function is to reduce both the network losses and regulate the voltage level under different loading conditions.
\end{abstract}

Index Terms- Distributed Generation (DG), Distribution systems, optimal DG allocation and Genetic Algorithms (GA)

\section{Introduction}

There has been an increasing improvement in the operation of Distributed Generation (DG) equipment; this development has made it a key part of power systems. DG source include diesel, fuel cells and renewable energy (RE), e.g. photovoltaic (PV) systems and wind turbines. As long as there is source of fuel available and there is easy connection to consumers, the DG can be placed anywhere.

There are key factors that should be taken into account when DGs are to be used, such as installation, sizing, types and location within the distribution network. In general, over sizing of the DGs can lead to reverse power flow through the distribution transformer and hence affecting the protection system and accordingly increasing the overall costs [1].

Due to the intermittency nature, DGs size and location that are not carefully considered may have negative effects on DN performance for example voltage stability, feeder capacity and the reverse power flow. Consequently, optimisation of size and location of DG units in distribution network aims to decrease system losses enhance system voltage profile, improve stability, reliability and security $[2,3]$.

Researchers have focused on developing methodologies for minimising power losses [4]. Many examples for such works are analytical methods [5-9]. Reference [9] presents development of Analytical expressions for optimal allocation of DG to reduce total real power losses in DN.

There have been many developed algorithms and solutions that can be used to investigate the allocation of DG in a DN. The differences among these algorithms are about the formulation of the problem, the proposed techniques and their assumptions. These reported methods include Genetic Algorithm (GA), Particles Warm Optimisation (PSO), Fuzzy Logic (FL), Eigen-Value based Analysis (EVA), Honey Bees Mating Optimisation (HBMO), Simulated Annealing (SA), Index Method (IM), Non-dominated Sorting Genetic Algorithm -II (NSGA-II), Artificial Neural Network (ANN), Body Immune Optimisation (BIA), Ant Colony Optimisation (ACO), Linear Programming (LP) etc. [12-17].

GA and PSO have been used for losses minimisation and voltage profile improvement [15], Fuzzy logic is utilized to minimise number of DGs to be connected and power losses [16] and ACO method is used to improve voltage stability [17]. This work uses GA techniques, as outlined below.

GA is an easy and simple to understand and it does not need complex mathematics knowledge [2]. Optimisation using GA offers a powerful tool to gain the optimal location of the DG in distribution network. In general, an initial population set, that are randomly selected from the achievable solution space, is used to run the GA. For each solution, the fitness function is evaluated and, therefore, the resulting solutions are categorised. The population then evolves through numerous operations for example; reproduction, crossover, and mutation to find the optimal fitness function and achieve the final optimal solution. The procedure is done many times until a termination criterion is met [15].

In this paper, a methodology will be suggested for optimal allocation of high penetration of wind energy DG in a DN using GA and PF. It is ordered as follow; Problem formulation in Section 2, case study in section 3, Results and discussion in section 4 and the conclusion in Section 5. 


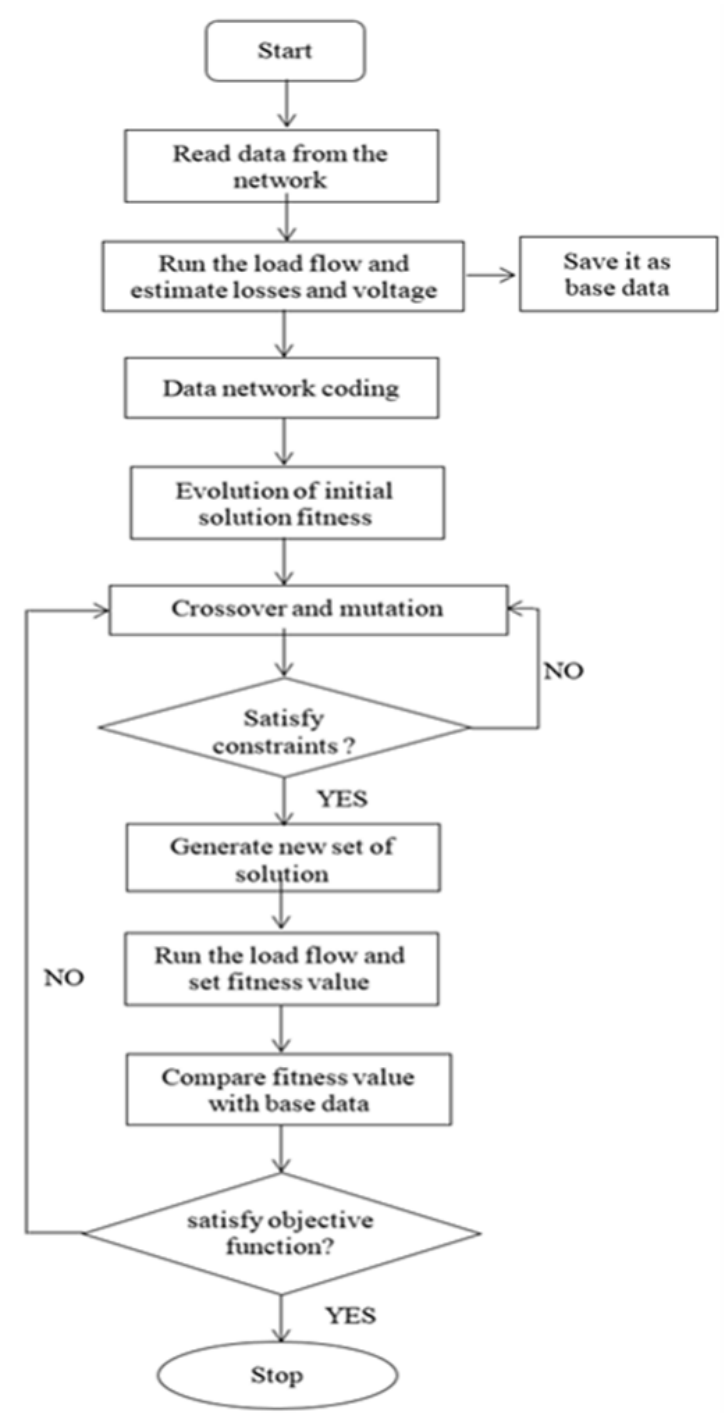

Figure 1: Flow chart of the GA method

\section{Problems formulation}

\subsection{Optimal size and location of $D G$}

The main goal of the proposed algorithm is to determine the best size and locations for new DG resources by minimising system objective function. In this work, two goals for determining the formula are used as starting point, they are;

- $\quad$ Reducing loss

- Improving voltage profile

Figure1 shows the flow chart of optimal sitting and sizing of distributed generation using GA.

\subsubsection{The objective function}

The objective function is formulated mathematically as:

$f=\min \left(k_{1} f_{1}+k_{2} f_{2}\right)$ $\mathrm{f}_{2}$ : network voltage profile per unit (p.u.)

$k_{1}$ and $k_{2}$ are penalty coefficients

$f_{1}=\sum_{j=1}^{m}\left(P_{\text {Loss with } D G}-P_{\text {Loss without } D G}\right)$

$f_{2}=\sum_{j=1}^{n}\left(V_{i \text { with } D G}-1\right)$

$n$ : number of buses

$m$ : number of branches.

\subsubsection{Power flow Constraints}

To get high penetration of renewable energy, the annual predicted wind energy and the load model are integrated into PF which is used to find the amount of wind energy that avoids violation of the system constraints.

Optimisation constraints are as follows:

$>$ quality Constraints:

Load balance constraint:

$P G_{i}+P D G_{i}-P L_{i}=\sum_{j=1}^{N} V_{j} * V_{i} * Y_{i j} * \cos \left(\theta_{i j}+\delta_{j}-\right.$

$\left.\delta_{i}\right)$

$Q G_{i}-Q L_{i}=\sum_{j=1}^{N} V_{j} * V_{i} * Y_{i j} * \sin \left(\theta_{i j}+\delta_{j}-\delta_{i}\right)$

$P G_{i}$ : Substation active power .

$P D G_{i}$ :Power output of the wind-based DG connected at bus. $P L_{i}$ : Active load at bus at time .

$V_{i}$ : Voltage at bus $i$.

$\theta$ : Moving average parameters.

$Q G_{i}$ : Substation reactive power.

$Q l_{i}$ : Reactive load at bus i.

$>$ Inequality Constraints:

1) Slack bus voltage and angle (assumed to be bus 1):

$$
V(1)=1.0 \quad \delta_{-}(1)=0
$$

2) Voltage limits at the other buses:

$$
V_{\min } \leq V_{i} \leq V_{\max }
$$

3) Line capacity limit

$$
0 \leq I_{i j} \leq I_{i j \max }
$$

$I_{i j}$ : Current in the feeder connecting busses $\mathrm{i}$ and $\mathrm{j}$.

4) Revers Power: The total number of wind turbine is determined as high penetration of renewable energy by using wind turbines

$$
\begin{gathered}
-0.75 * R \leq P G_{i} \leq R \\
R: \text { Substation rating. }
\end{gathered}
$$

This constraint guarantees that the reverse power will not be more than 0.75 of the substation rating.

5) Number of DG (wind turbine units) on the bus should be less than the number of homes on the same bus

6) Loss with $\mathrm{DG} \leq$ Loss without DG.

$\mathrm{f}_{1}$ : Network real power losses 


\subsection{Modelling of Wind speed}

In this model of wind turbine, a selected study period of one year is divided into four seasons, i.e. Winter, Summer, Spring \& Autumn. A typical day is generated for each season in order to represent the random behaviour of the wind speed during each period. Hourly wind speed data from 2011 to 2014 were used to calculate an hourly mean over this period. This data is collected from Met Office Library \& Archive [18] from the station weather at Glasgow Bishopton. The data for a typical day in each season is further subdivided into 24hour segments (time segments), each referring to a particular hourly interval for the entire season. For simplicity, each month is considered as 30 days. Based on the wind speed, power was calculated by using Curve fitting of a typical 11 $\mathrm{kW}$ wind turbine performance characteristics. Figure 2 shows the variation in power output for the different seasons.

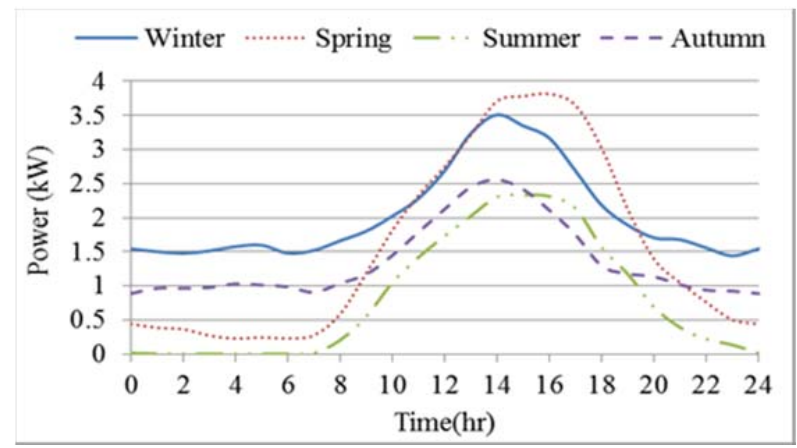

Figure 2: Power variation of Wind Turbine.

\subsection{Modelling of Load}

The load demand is obtained from historical data for the UK power network. This system provides half-hourly peak load. The daily load profile of the UK distribution networks for four seasons are shown in the Figure 3 below, as can be seen data differs from season to season (Load factor: Winter $=1$, Summer $=0.5$, Spring \& Autumn $=0.75)$ [14].

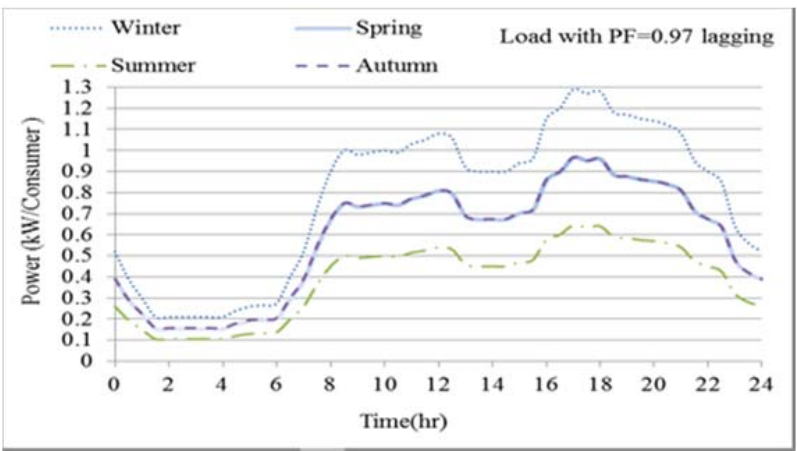

Figure 3: Average Daily load in the UK distribution network

\subsection{Hourly electricity price modelling}

Figure 3 above also shows that the electricity usage in the UK has a regular pattern with higher electricity demand in the daytime between 08:00-22:00 (considered as peak in this work) and the lowest usage of electricity are in the late night between 22:00-08:00 (considered as off-peak).

\section{CASE STUDY}

The single line diagram of the LV distribution network in the UK is used in this work, its substation contains an 11/0.4 KV transformer, rated at 0.5 MVA with 384 consumers.

Table1 shows line and bus information [14]. The proposed method for optimal sitting and sizing of DG has been implemented in the MATLAB.

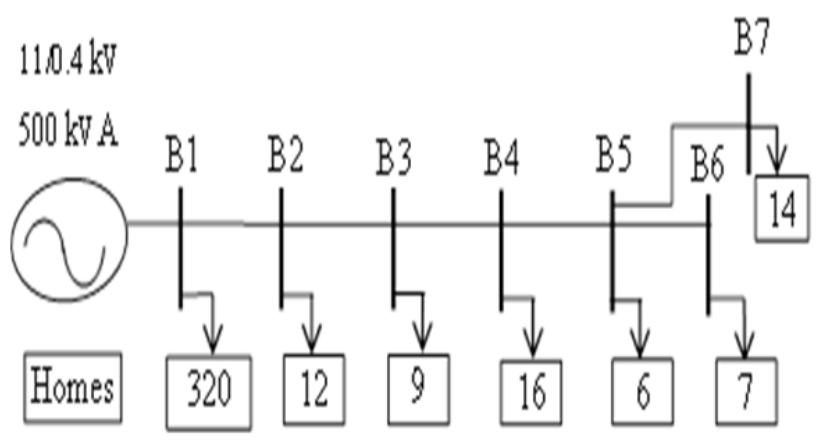

Figure 4: LV distribution network in the UK

Table 1: line and bus information for Spring Season

\begin{tabular}{|c|c|c|c|c|c|c|c|}
\hline \multirow{2}{*}{ 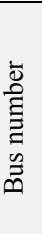 } & \multirow{2}{*}{ 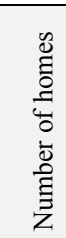 } & \multicolumn{2}{|c|}{$\begin{array}{l}\text { Load power } \\
\text { at peak power of } \\
\text { DG (spring } \\
\text { season) }\end{array}$} & \multirow{2}{*}{ 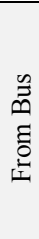 } & \multirow{2}{*}{ 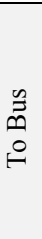 } & \multirow{2}{*}{$\underset{\Omega}{\Omega}$} & \multirow{2}{*}{$\underset{x}{\hat{\theta}}$} \\
\hline & & $\mathrm{P}(\mathrm{kW})$ & Q (kva) & & & & \\
\hline 1 & 320 & 382 & 70.5 & 1 & 2 & 0.078 & 0.0223 \\
\hline 2 & 12 & 9.49 & 2.37 & 2 & 3 & 0.106 & 0.0292 \\
\hline 3 & 9 & 6.9 & 1.72 & 3 & 4 & 0.048 & 0.0080 \\
\hline 4 & 16 & 12.93 & 3.23 & 4 & 5 & 0.052 & 0.0084 \\
\hline 5 & 6 & 3.45 & 0.86 & 5 & 6 & 0.09 & 0.0146 \\
\hline 6 & 7 & 5.17 & 1.29 & 5 & 7 & 0.138 & 0.0225 \\
\hline 7 & 14 & 11.21 & 2.8 & & & & \\
\hline \multicolumn{2}{|c|}{ Total } & 331.2 & 82.8 & & & & \\
\hline
\end{tabular}

\section{Results and discussion}

The studies of PF are investigated using MATLAB. The modified DN, which has 6 lines, is used to validate the effectiveness of GA. It is assumed that all the loads are fed from the substation. 
In this report the variation in wind power generation over a year has been analysed to find the number of wind turbine units to get a High Penetration of Wind Energy. These wind turbines will supply the system for the whole year. The number of wind turbines for the whole system is 186 units and the maximum power based on wind availability is $3.871 \mathrm{~kW}$.

Winter season has been used for this analysis because it has the highest load as shown in Figure 5.
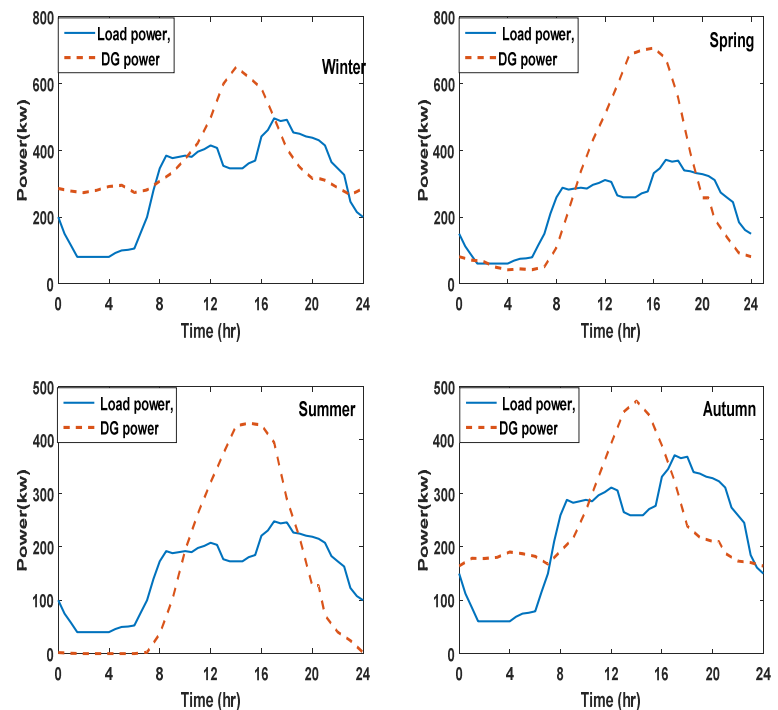

Figure 5: Power of daily Home loads, and total DG (Wind) production for the whole year.

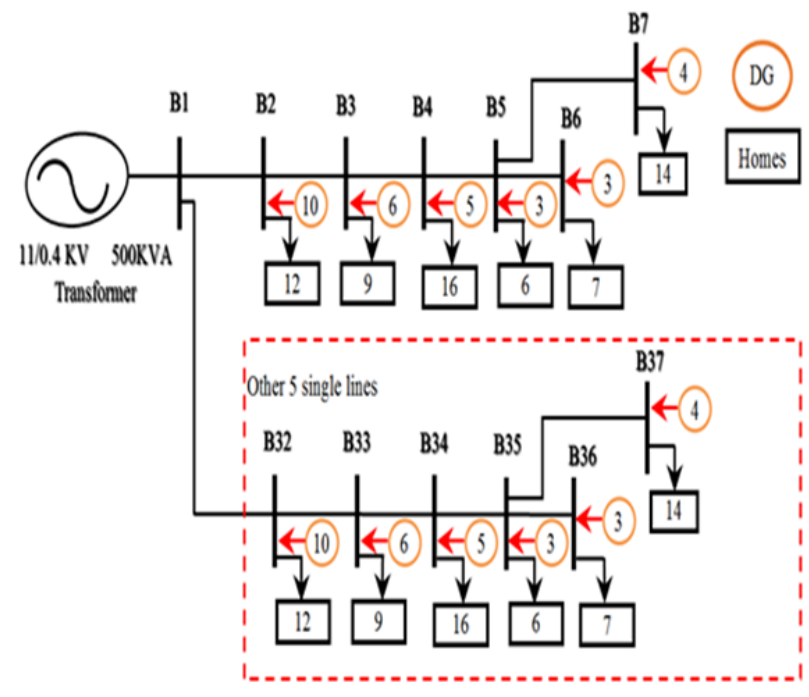

Figure 6: Tested LV network with distributed DG using GA.

\subsection{Improve voltage and decrease power loss using GA:}

From Figure 5, it can be seen that the spring season has the highest wind power $\sim 700 \mathrm{~kW}$ at time 16.00 when load demand is $331.2 \mathrm{~kW}$. $700 \mathrm{~kW}$ is considered to be the maximum DG power for the whole system and it has been used in GA and OPF because this value has the highest reverse power which is around $371 \mathrm{~kW}$. The GA program output for 4 trials are tabulated in Table 2 and 3 . As presented in Table 2, and shown in Figures 7 and 8, the allocation of DG units in various buses with the rated values shows clear improvement in voltage control and decrease in real power losses. Table 3 shows the number of DG for each bus calculated from Table 2. From the 4 trials, it is clear that the number of DG for each bus is relatively consistent. From Figure 7 and 8 , Trials $2 \& 3$ has the same settings and has the lowest power losses and PU voltages closer to 1 .

Table 2: GA Result (DG power $(\mathrm{kW})$ for each bus for 4 trials)

\begin{tabular}{|c|c|c|c|c|c|c|c|c|}
\hline Trial & B1 & B2 & B3 & B4 & B5 & B6 & B7 & Total \\
\hline 1 & 0 & 218.3 & 128.1 & 106.5 & 85.9 & 71.4 & 88.8 & 700 \\
\hline 2 & 0 & 244.2 & 128.1 & 107 & 80.2 & 59. & 81.4 & 700 \\
\hline 3 & 0 & 241.6 & 136.3 & 103 & 74.5 & 68.3 & 76.4 & 700 \\
\hline 4 & 0 & 219.8 & 135.4 & 112.8 & 80.4 & 69.4 & 82.0 & 700 \\
\hline
\end{tabular}

Table 3: GA Result (number of wind turbines per bus, 4 trials)

\begin{tabular}{|c|c|c|c|c|c|c|c|c|}
\hline Trial & B1 & B2 & B3 & B4 & B5 & B6 & B7 & Total \\
\hline 1 & 0 & 9 & 6 & 5 & 4 & 3 & 4 & 31 \\
\hline 2 & 0 & 11 & 6 & 5 & 3 & 3 & 3 & 31 \\
\hline 3 & 0 & 11 & 6 & 5 & 3 & 3 & 3 & 31 \\
\hline 4 & 0 & 10 & 6 & 5 & 3 & 3 & 4 & 31 \\
\hline
\end{tabular}

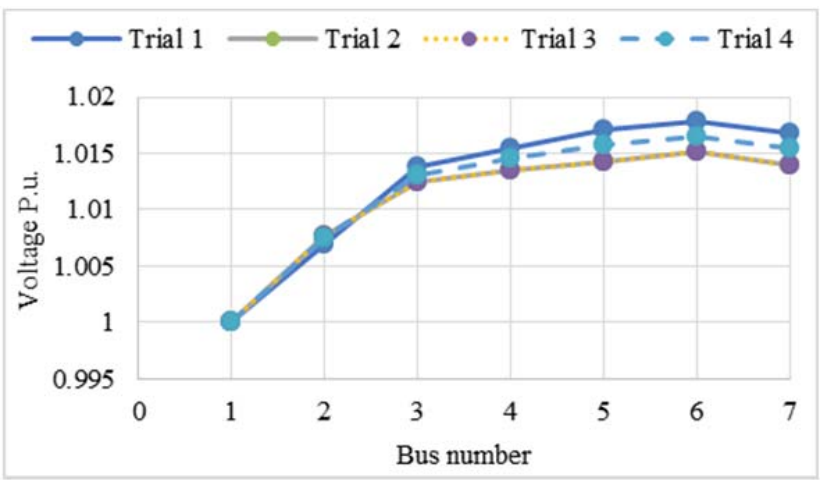

Figure 7: Voltage from GA result for 4 trials during peak of DG

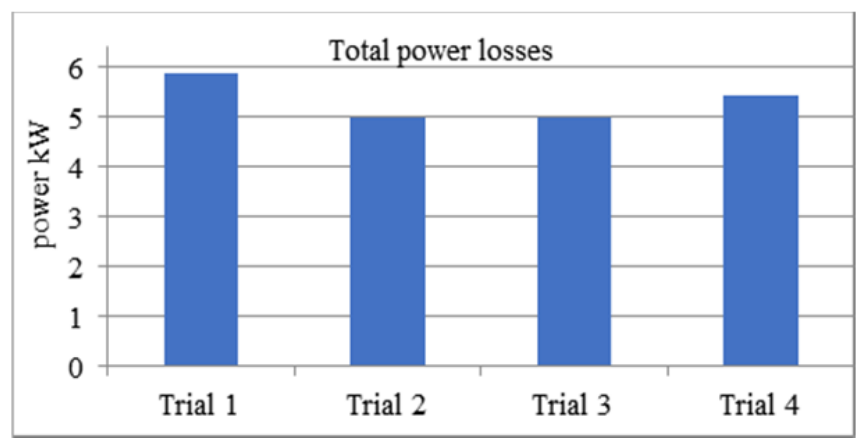

Figure 8: Total power losses from GA result for 4 trials during peak of DG 


\subsection{Different case studies for tested system:}

Three different case studies for the tested system are shown in the Figures 4, 6 and 9 which are:

a) Base case (no DG) - Fig. 4

b) With DG (arbitrary non-optimal regular distribution ) - Fig. 9

c) With DG distributed (using GA method ) - Fig. 6

The real Power loss and voltage with/without DG for different cases are shown in the figures 10 and 11 . The same number of DG units (186) has been used in both cases (b) and (c). In case (b), the worst case, there is no DG on the buses2 to 7 in line 1 whereas the other 5 lines have 37 DG each, as shown in Figure 9. By using GA in case (c), , the optimal distribution of DG has been found, i.e. 31 for each line, as shown in Figure 6 and Table 3.

From Figure 10, the real power losses in case (b) is quarter of the power losses in case (c) whereas case (a) is slightly more than case (c). Figure 11 shows that the p.u. voltage in case (b) is close to unity whereas case (c) and (a) are farther from unity.

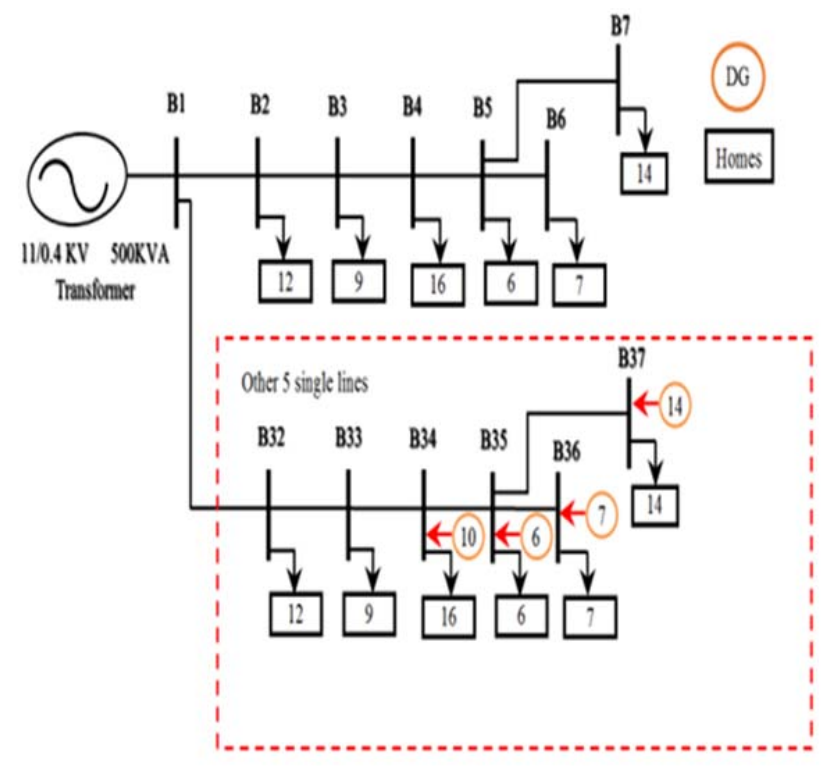

Figure 9: Tested distribution network with DG (arbitrary non-optimal regular distribution).

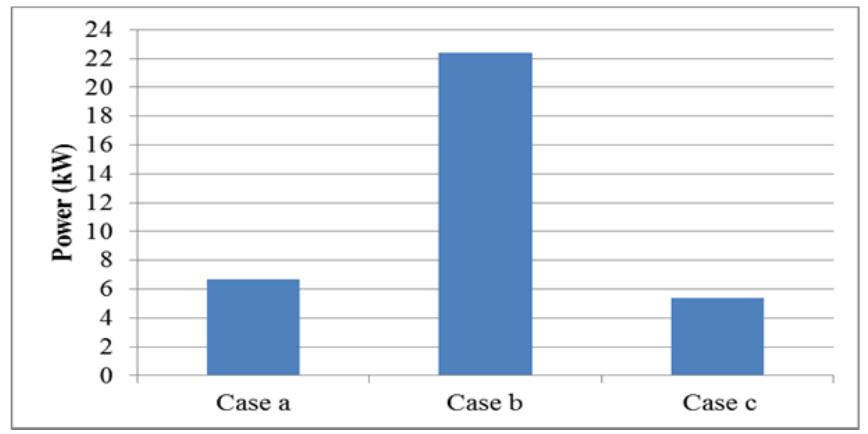

Figure 10: Total power losses of the tested system with and without DG

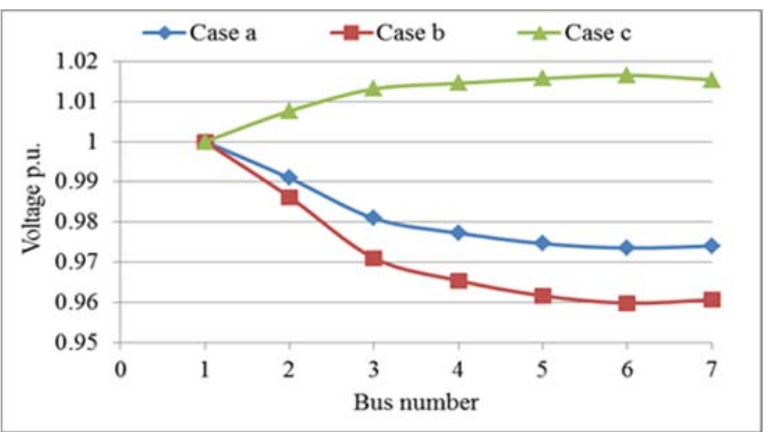

Figure 11: PU Voltages of the tested systems with and without DG.

\subsection{Winter season:}

The variation in load demand and power of DG are presented for 24 hours in a day in winter as shown in figure 5.

Figure 12 presents the real power losses of the three cases a,b and $\mathrm{c}$. There is a significant drop in the real power losses of the network when DG is included.

After DG placement, the real power loss peak of $15.3 \mathrm{~kW}$ at $17: 00$ in case a drops to $6.1 \mathrm{Kw}$ in case $\mathrm{b}$ whereas $1.15 \mathrm{~kW}$ in case $\mathrm{c}$.

At 14:00, when total DG power peaks at $650 \mathrm{~kW}$ and load power $345 \mathrm{~kW}$, in case c the peak reverse power is $301 \mathrm{~kW}$ and power real power losses are $4 \mathrm{~kW}$, as shown in Figure 12 $\& 13$.

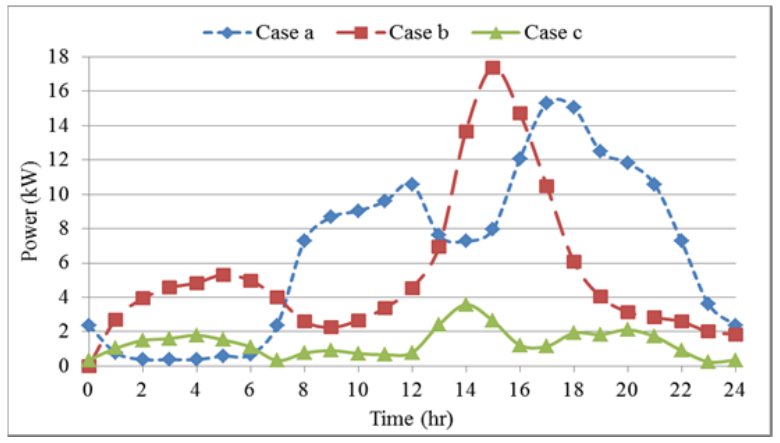

Figure 12: Comparison of total power losses of the system with/without DG for one day in winter season.

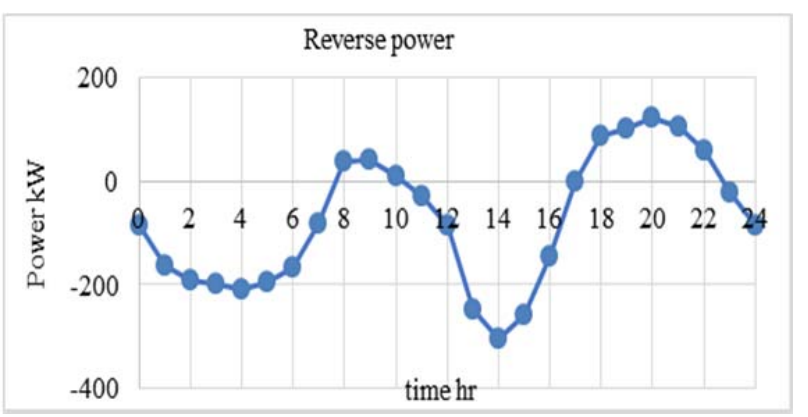

Figure 13: Reverse power with DG using GA for one day in winter season

Figure 14, 15 and 16 shows comparative system voltage profile during winter day between the case $a$, case $b$ and case c.it can be seen in figure 17 that voltage profile of the system improved and is now near the unity value or the 1.0 p.u. voltage. 


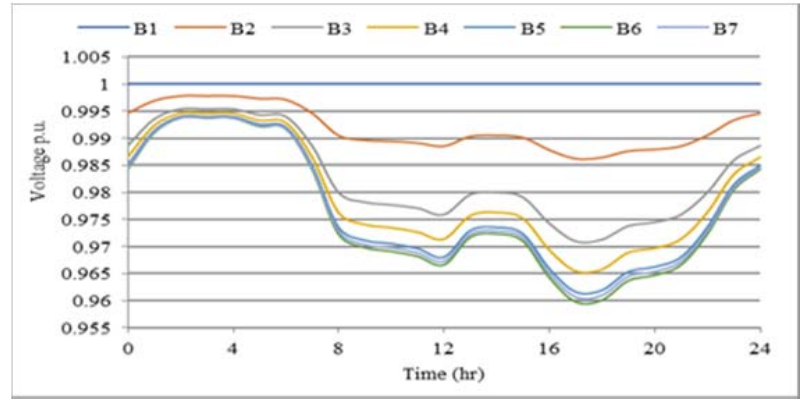

Figure 14: Voltage for system feeders B1 to B7 without DG for one day in winter season.

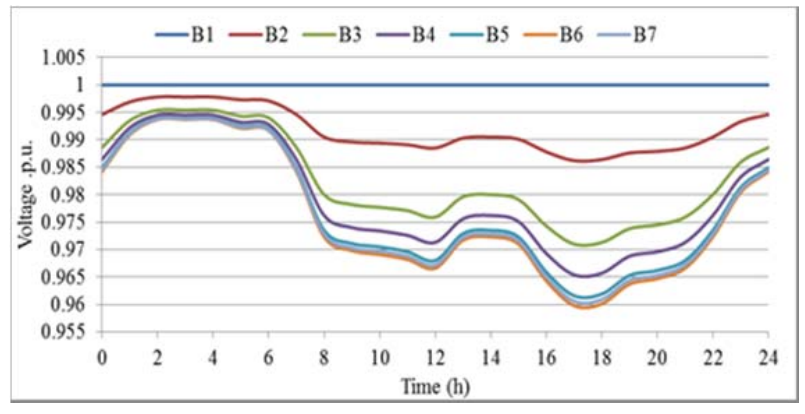

Figure 15: Voltage for system feeders B1to B7 with DG (arbitrary non-optimal regular distribution) for one day in winter season.

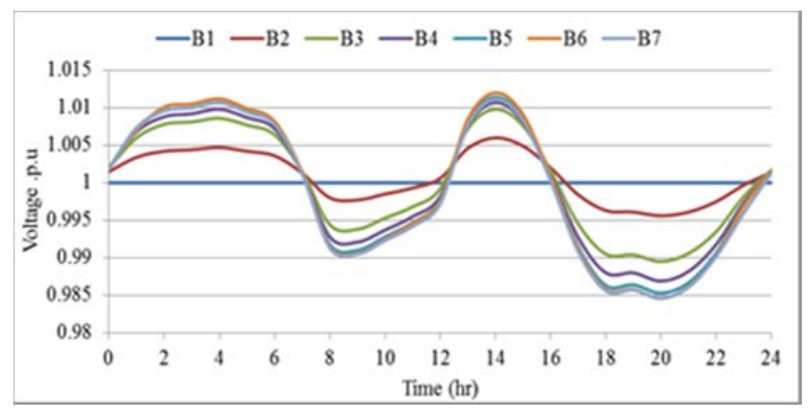

Figure 16: Voltage for system feeders B1to B7 with DG (using GA) for one day in winter season

\section{Conclusion}

Genetic algorithms (GA) can be utilized in finding the optimal solution compared to manually searching for the optimal location to place and the size DG units in a DN. The proposed technique is based on power flow (PF) formulations and the data are integrated into PF formulations to determine power losses and voltage. The chosen objectives of reducing the real power losses and improvement of voltage profile have been reached. This proposed algorithm is differ from the other works, it worked with small scale of DG based on number of homes on the same bus.

\section{REFERENCES}

[1] S. Das, D. Das, and A. Patra. "Distribution network reconfiguration using distributed generation unit considering variations of load." In Power Electronics, Intelligent Control and Energy Systems (ICPEICES), IEEE International Conference on, pp. 1-5. IEEE, 2016.

[2] P. Prakash, and DK. Khatod. "Optimal sizing and siting techniques for distributed generation in distribution systems: A review." Renewable and Sustainable Energy Reviews 57 (2016): 111-130.

[3] T., Shukla, S. Singh, and K. Naik. (2010). "Allocation of optimal distributed generation using GA for minimum system losses in radial distribution networks." International Journal of Engineering, Science and Technology 2, no. 3: 94-106.

[4] P.S., Georgilakis, and N.D., Hatziargyriou. "Optimal distributed generation placement in power distribution networks: models, methods, and future research." IEEE Transactions on Power Systems 28, no. 3 (2013): 3420-3428.

[5] C., Wang, and M.H., Nehrir. "Analytical approaches for optimal placement of distributed generation sources in power systems." IEEE Transactions on Power systems 19, no. 4 (2004): 2068-2076.

[6] T., Gözel, and M.H., Hocaoglu. "An analytical method for the sizing and siting of distributed generators in radial systems." Electric Power Systems Research 79, no. 6 (2009): 912-918.

[7] N., Acharya, P., Mahat, and N., Mithulananthan. "An analytical approach for DG allocation in primary distribution network." International Journal of Electrical Power \& Energy Systems 28, no. 10 (2006): 669-678.

[8] M. Zidar, P.S. Georgilakis, N.D. Hatziargyriou, T.Capuder and D. Škrlec. "Review of energy storage allocation in power distribution networks: applications, methods and future research". IET Generation, Transmission \& Distribution, 10, no. 3, (2016), pp.645-652.

[9] D.Q., Hung, N., Mithulananthan, and R.C., Bansal. "Analytical expressions for DG allocation in primary distribution networks." IEEE Transactions on energy conversion 25, no. 3 (2010): 814-820.

[10] W., Sheng, KY., Liu, Y., Liu, X., Meng, and Y., Li. "Optimal placement and sizing of distributed generation via an improved nondominated sorting genetic algorithm II." IEEE Transactions on Power Delivery 30, no. 2 (2015): 569-578.

[11] J.J., Jamian, M.W., Mustafa, and H., Mokhlis. (2015). "Optimal multiple distributed generation output through rank evolutionary particle swarm optimisation." Neurocomputing 152: 190-198.

[12] B., Singh, V. Mukherjee, and P., Tiwari. (2015). "A survey on impact assessment of DG and FACTS controllers in power systems." Renewable and Sustainable Energy Reviews 42: 846-882.

[13] V. V. S. N., Murthy, and A., Kumar. (2013). "Comparison of optimal DG allocation methods in radial distribution systems based on sensitivity approaches." International Journal of Electrical Power \& Energy Systems 53: 450-467.

[14] P., Suwanapingkarl. "Power quality analysis of future power networks." PhD diss., Northumbria University, 2012.

[15] M.H., Moradi, and M. Abedini. "A combination of genetic algorithm and particle swarm optimisation for optimal DG location and sizing in distribution systems." International Journal of Electrical Power \& Energy Systems 34, no. 1 (2012): 66-74.

[16] M., Esmaili. "Placement of minimum distributed generation units observing power losses and voltage stability with network constraints." IET Generation, Transmission \& Distribution 7, no. 8 (2013): 813-821.

[17] M., Kefayat, A.L., Ara, and S.N., Niaki. "A hybrid of ant colony optimisation and artificial bee colony algorithm for probabilistic optimal placement and sizing of distributed energy resources." Energy Conversion and Management 92 (2015): 149-161.

[18] Met Office Library \& Archive (2016). Hourly wind data for Glasgow . Available: http://www.metoffice.gov.uk 